\title{
Analysis on the Socio-economic and Victimization aspect of the Victims in Nepal Lok Bahadur Shah ${ }^{1} \&$ Dr. Nutan Chandra Subedee ${ }^{2}$
}

${ }^{1} \mathrm{PhD}$ Scholar, Mewar University, Rajasthan, India

${ }^{2}$ Associate Prof. Nepal Law Campus, Tribhuvan University, Kathmandu, Nepal

\section{Corresponding Author}

Lok Bahadur Shah

ims2065@gmail.com

\begin{abstract}
This article is based on the study carried out in order to gauge the present scenario of crime and victimization in relation to socio-economic status of the victims. The purpose of this study was to analyze the victimization as well as socio-economic aspect of the victims of Nepal. The present scenario is that the crime and victimization are two sides of a coin and socio-economic condition of the society is one of the major factors on which it depends. The society with sound socioeconomy has fewer criminal activities and fewer records of victimization. The study was based on primary data collected from the field survey. The crime victims, dependents of the victims and some key persons were the real respondents of this study. In depth interview, key informant's interview, group discussion and published and unpublished documents were also used in this study. To make it more relevant, the data were analyzed by using interpretation, explanation and analysis. The result of the study shows that victimization mostly takes place in the society where people are long time inhabitant, uneducated, having large family size with gender discrimination as well as traditional farming and unemployment resulting in poor economic condition. Vulnerability of victims and their dependent is the outcome of their poor socio-economic status.
\end{abstract}

\section{KEYWORDS}

Crime, dependents, first information report, income, justice, discrimination, victims

\section{INTRODUCTION}

All the people be happy, they feel peace and security, all people see good, no one feels problem and all of them get justice are the fundamental bases of the civilized society and society runs to achieve these goals. Peace, security and development of the society depend upon the justice and justice secures peoples' freedom, life guarantee, independent existence and the overall development of the human life. By which, the concept of equality before the law and equal protection of law is born and raised. But from the time of human origin and development, many 
problems have existed in the society. Civilization and the crime both started simultaneously where the institutions of justice had also been played a great role though they were not systematic and organized. Victims of crime may be of any gender, age, race, or ethnicity individual, family, group, or community can go through Victimization; a person or property itself might fall prey to the crimes. The impact of crime on an individual victim, their dependents, and their community depends on a variety of factors, but often crime victimization has significant emotional, psychological, physical, financial, and social consequences. But when we go through the history of crime, victimization and justice, we often find socio-economic condition to be the major factor. The methodology of crime, the way people become victimized and the way victims get justice are mainly dependent on the socio-economic status of the people in the society. The society with well economic status may face very fewer and minor cases of victimization as Smith and Jarjoura (1989), has mentioned that if the society is stable socially and economically with high income, there is a low chance of encountering cases of victimization (p.662).

While observing crime on the basis of social phenomenon, education plays a vital role. The rate of engagement in criminal activities is found high among the people who are less educated because they are not enough aware about the law and order about the society as well as country. Lack of awareness is one factor that leads them to engage in criminal activities because they are not able to think about the result of crime before they get themselves involved in it. Mostly, the conflicts are also found among the people of uneducated family and society as a result of their unemployment situation. At the same time, education, awareness, training and other academic factors owe to improve one's earnings as well as develop the human capital as Lochner, (2004) has stated "The human capital approach, in its simplest form, stresses the role of wages and opportunity costs in determining criminal activity, arguing that older, more intelligent, and more educated individuals commit less crime because they have more human capital and can earn higher wages."(p. 812).

Age plays an important role for human growth and development; it is also a social factor that affects social transformation as well as psychological and legal. Time factor plays a vital role in the achievement of the social and economic goal. It is mainly related with the legal factor because all the activities of the society are mostly related with rules and regulations of the society. Age group of the people in the society is another major factor responsible for crime and victimization. The child and old people are mainly found at risk of being victimized. Children and old people are not enough capable to distinguish the criminal activities. Likewise involvement in crime also depends on an individual's age factor because growing maturity with academic environment as well as physical development results development in social network as Lochner (2004) has indicated that sociologists and criminologists stress biological development, maturity, and/or the establishment of social networks, families, and norms as other channels through which age and education may affect decisions to engage in crime. Gender is another determinant for the crime and victimization in the society. Rate of victimization is often seen 
high among female in the society. Female are not considered as strong as male in the family owing to various factors. The value of family towards females is not as strong as towards male. Daughters are given the task of household activities which keeps them from becoming stronger mentally, socially and physically as Downey, (1994) has put the view that there are several reasons to believe that sex composition affects certain parental attitudes and values. Feminist scholars and other social scientists have established that individuals tend to act on the basis of their gender and the gender of others in a variety of contexts. Just as individual behavior is influenced by gender, groups may operate differently on the basis of their sex composition. They are given less chances to involve in the activities outside the household one which keeps them from knowing about the crime and criminal activities, as a result they become easy targets for the criminals. It has also been seen that most of the victims are females in the study area. As we know that our society is composed of patriarchal systems male are rarely victimized.

Observing the crime from the economic perspective, it is one of the influencing factors in the human society. Economic earning, poverty level and business of an individual always play major role in crime. Considering the fact, Mckeown (1948) has said that there is a close relation between poverty and criminal activities in which person can be attracted towards crime due to poverty (p. 1). Naturally, if the person is busy mentally and physically, there is less chance of $\mathrm{him} /$ her getting involved in criminal activities. The financial crisis could lead to 'increased crime rate' - certainly appears to be plausible. Criminal motivation theories, including strain theory, propose that illicit behaviors are caused, at least in part, by structurally induced frustrations at the gap between aspirations and expectations, and their achievement. Where the financial crisis is manifested through decreased or negative economic growth and widespread unemployment, large numbers of individuals may suffer severe and perhaps sudden reductions in income. In this regard Hirschi (1969) has said that social control theories predict that employment is perceived as conventional behavior and serves to reinforce social bonds and activate social control, it also acts to reduce involvement in criminal activities. So, it can be said that economic hardship brings people to engage in criminal activities and if that happens in the society another person in the society automatically becomes the victim as Hale and Sabbagh (1991) has expressed that economic hardship produces a stressful situation of shortage, which, in turn, may increase the chances of people turning to crime to provide for individual or family needs. So it can be said that differences in economic status in the society contributes towards the increment in crime rate in the society and if so there would be same situations of victimization as Gilbert(2008) has intended to point. He says income inequality is significantly and positively related to the incidence of crime within and between countries. In other words, the higher the gap of income level, the higher the rate of crimes.

\section{METHOD}

This study is mostly based on direct in-depth interview with respondents or victims. Key informant interviews were also carried out. A list of semi-structured questions and checklist were developed and pre-tested before the interview. The responses were recorded through tape 
recorder, video and photographs. The data/information obtained from the victims is the primary in nature. Similarly, information obtained from reviewing constitutions, acts, rules, regulations, laws, precedents, legal and appellate/supreme court decisions are secondary data. The data were collected from the primary and secondary sources by using the data collection tools. The study was based on the secondary data so more secondary data were collected to meet the objectives of research. Various literatures relevant to the study published or unpublished in Nepal and abroad were reviewed for the collection of secondary data. This research is mostly based on data available from the crime victims and their dependents. It is also based on previously published literatures and secondary information. A lot of data have been used to explain and justify the concepts. Qualitative as well as quantitative data have supported the argument. There are various sources of data and information that vary in nature.

\section{RESULT AND DISCUSSION}

This section deals with analysis and interpretation of data collected through the field survey. The analysis has been made on the basis of socio-economic background of the respondents' age and sex, duration of living in the study area, family size, and type of family, literacy rate as well as status of victimization in relation to victimization by types of crime, waiting duration and court procedures. This chapter also deals with the description and analysis of the impact of economic affairs, situation of status, level of poverty and occupation on the process of victimization of the respondents in the study area. Economic activities of people help to sketch the actual condition of livelihood because they are interconnected with people as well as psychological sphere of the society. Economic situation regulates entire activities of the society. If economic condition of people is sound in the study area, we come to know that the living standard is better and they can overcome any other issues related with legal affairs, with little effort. In other words, this chapter deals with all the data related to economic and social sector of the respondents in the study area.

\section{Duration of stay in the study area}

People do not migrate from one place to another if they are busy in traditional occupation because such occupation always needs generations to run the same occupation and they can continue it without any proper training and extra knowledge which makes them stay longer time at a place. Though few members of the family migrate, older generations desire to stay at their and the very traditional place. So, living years of the respondents show that they have very long history of living at the place following social norms and values which have been supporting them to run their society peacefully. They enjoy and participate in different social and cultural activities. Due to the long span of the respondents stay at that place, they are familiar with the environment along with culture and they have knowledge about every events of the society, such as criminal activities and the cases of victimization, which are mainly related to the social phenomenon as Lamond (2007) has clearly mentioned that crimes are not simply artificial 
creations of the law or a negative covenant. Instead, criminal law has a crucial social dimension. The table below shows an explicit picture of the respondents living in the study area. The field survey of Banke District Court and Appellate Court Nepalgunj makes estimation to draw a conclusion stay at local place from the table below:

Table No 1: Duration of the stay in the study area

\begin{tabular}{|l|l|l|l|}
\hline S.N & Years & No. of respondents & Percentage \\
\hline 1 & $1-5$ & 4 & $14.29 \%$ \\
\hline 2 & $5-10$ & 7 & $25 \%$ \\
\hline 3 & 10 and More & 17 & $60.71 \%$ \\
\hline & Total & $\mathbf{2 8}$ & $\mathbf{1 0 0 \%}$ \\
\hline
\end{tabular}

\section{Source: Field Survey, 2015}

The table above shows information about the respondents' living years in the study area. It is obvious from the study that 17 people $(60.71 \%)$ out of 28 have been residing for more than 10 years in the study area which covers highest percentage. This signifies about their familiarities with culture, climate and occupation of that area. Similarly, 25 percent (7) have been living there from 5-10 years followed by 14.29 percent (4) people living there from 1-5 years.

\section{Age and sex structure of the respondents}

Age plays an important role for human growth and development. It is also a social factor that affects social transformation as well as psychological and legal. Time factor plays a vital role in the achievement of the social and economic goals. It will be mainly related with the legal factor because all the activities of the society are mostly related with rules and regulations of the society. Age of the respondents have been arranged into six categories i.e.; 10- 20, 20-30, 30-40, 40-50, 50-60 and 60 years and above respectively. The information is displayed on table.

Table No. 2: Distribution of respondents by sex and age

\begin{tabular}{|l|l|l|l|l|l|}
\hline \multirow{2}{*}{ S.N. } & \multirow{2}{*}{ Age in years } & Sex & \multirow{2}{*}{ Total } & \multirow{2}{*}{ Percent } \\
\cline { 3 - 5 } & & Male & Female & & \\
\hline 1. & $10-20$ & 0 & 5 & 5 & $17.89 \%$ \\
\hline 2. & $20-30$ & 1 & 9 & 10 & $35.71 \%$ \\
\hline 3. & $30-40$ & 2 & 1 & 3 & $10.71 \%$ \\
\hline 4. & $40-50$ & 3 & 2 & 5 & $17.89 \%$ \\
\hline
\end{tabular}




\begin{tabular}{|l|l|l|l|l|l|}
\hline 5. & $50-60$ & 2 & 0 & 2 & $7.14 \%$ \\
\hline 6. & $60-70$ & 2 & 1 & 3 & $10.71 \%$ \\
\hline & Total & $\mathbf{1 0}$ & $\mathbf{1 8}$ & $\mathbf{2 8}$ & $\mathbf{1 0 0}$ \\
\hline
\end{tabular}

Source: Field survey, 2015

The table above displays information of the respondents by age and sex. The study area has the highest population of people of the age group of 20-30 i.e. $35.71 \%$. Similarly, $17.89 \%$ people belong to the age group 10-20 and 40-50. Similarly, $10.71 \%$ people there fall under the age group $30-40$ and $60-70.7 .14 \%$ of the population there is of age group 50-60. It seems that the study area comprises of more number of respondents of age 20-30 because people of that age group have more responsibility for household chores. But on the contrary, respondents of age group 50-60 and 60-70 are less in number because they are ageing people and slowly they might be handing over their responsibility towards young generation (the young members of their family) and might be keeping themselves free from household chores, their dependency might be on their children and they should not have to face many problems that leads towards victimization. The highest number of respondents is of age group 20-30 because those is the age in which they have to take family responsibility as well as have to involve in their personal development. During the process, they might have to face various social and economic as well as political problems that may cause the situation of victimization. Moreover, we can also analyze sex of respondents. Out of 28 respondents, 18 are females and 10 are males. The fact and figure helps to know the number of respondents according to sex in the study area, not only that it also reveals the fact that females' percentage is higher than the males in the case of victimization and they are in problem because our society is composed of patriarchal structure as Bari (2005) has coined that the gender role ideology is used as an ideological tool by patriarchy to place women within the private arena of home as mothers and wives and men in the public sphere.

\section{Status of victim and Dependents}

A person harmed by a crime or injured or killed or made to suffer is known as victim. Victims are individuals or groups directly or indirectly affected negatively from the activities of criminals or their family members. Various factors are taken into consideration to define victim. UN Basic Principle has stated that victim means person who, individually or collectively have suffered harm, including physical or mental injury, emotional suffering, economic loss or substantial impairment of their fundamental rights, through acts or omission that are in violation of criminal laws operative within member state, including those laws prescribing criminal abuse of power (UN , 1985). The following table shows the real picture of the victims among the respondents,

Table No. 3: Distribution of victims by age

\begin{tabular}{|c|c|c|c|c|c|}
\hline \multirow{2}{*}{ S.N. } & \multirow{2}{*}{ Age in years } & \multicolumn{2}{|c|}{ Victims } & \multirow{2}{*}{ Total } & \multirow{2}{*}{ Percen } \\
\hline & & Male & Female & & \\
\hline
\end{tabular}




\begin{tabular}{|l|l|l|l|l|l|}
\hline 1. & $10-20$ & 0 & 4 & 4 & $18.18 \%$ \\
\hline 2. & $20-30$ & 1 & 7 & 8 & $36.36 \%$ \\
\hline 3. & $30-40$ & 2 & 1 & 3 & $13.64 \%$ \\
\hline 4. & $40-50$ & 2 & 1 & 3 & $13.64 \%$ \\
\hline 5. & $50-60$ & 2 & 0 & 2 & $9.09 \%$ \\
\hline 6. & $60-70$ & 1 & 1 & 2 & $9.09 \%$ \\
\hline & Total & 8 & 14 & 22 & $\mathbf{1 0 0}$ \\
\hline
\end{tabular}

Source: Field survey, 2015

The table above displays information of the respondents by age and sex wise. In the study area, most of the victims are of age group 20-30 i.e.36.36\% whereas $18.18 \%$ people are of age group 10-20. Similarly, there are $13.64 \%$ victims who fall under the age group $30-40$ and $40-50$. As well as there are 9.09\% victims of age group 50-60 and 60-70. It seems that respondents having age 20-30 are more victims in number in the study area because people having that age group might be educated and have awareness about their rights which may bring their presence in court more than other age group people as well as early 20 s people have high ambition in their life. To fulfill their demands, they trust other people quickly as a result they may face several problematic situations and are easily victimized. But on the contrary, the number of victims is less in the age group 50-60 and 60-70 because they are ageing people and slowly they are leaving their responsibility from household chores, they do have no high ambition and as an experienced they would not believe others quickly. The people of age 10-20 are innocent and they are not mature enough to distinguish what is wrong and what is right as a result they can be close to anyone in a very short period of time and can trust on them. Such situation might lead them towards victimization.

\section{Status of Dependents}

Dependents are mostly ignored in the judicial system of Nepal because they are always hidden in the entire procedure of the case. But they too are like victim and should be kept in the category of victim and should be drawn inside the frame work of the human rights. Mainly, in any of the cases, with the victim, there is always a dependent. In this study area, the following situation of the dependents is exposed,

Table No. 4: Distribution of respondents by Dependents

\begin{tabular}{|l|l|l|l|l|l|}
\hline \multirow{2}{*}{ S.N. } & \multirow{2}{*}{ Age in years } & Dependents & \multirow{2}{*}{ Total } & \multirow{2}{*}{ Percent } \\
\cline { 3 - 4 } & & Male & Female & & \\
\hline 1. & $10-20$ & 0 & 1 & 1 & $16.67 \%$ \\
\hline 2. & $20-30$ & 0 & 2 & 2 & $33.33 \%$ \\
\hline 3. & $30-40$ & 0 & 0 & 0 & $0 \%$ \\
\hline 4. & $40-50$ & 1 & 1 & 2 & $33.33 \%$ \\
\hline 5. & $50-60$ & 0 & 0 & 0 & $0 \%$ \\
\hline
\end{tabular}

Vol. 3. No. I

www.phdcentre.edu.np 


\begin{tabular}{|l|l|l|l|l|l|}
\hline 6. & $60-70$ & 1 & 0 & 1 & $16.67 \%$ \\
\hline & Total & $\mathbf{2}$ & $\mathbf{4}$ & $\mathbf{6}$ & $\mathbf{1 0 0}$ \\
\hline
\end{tabular}

Source: Field survey, 2015

\section{Type of family of the respondents}

Family is the basic unit of a society. It is one of the oldest institutions of human society since time immemorial. It is a primary and universal group characterized by common residence performing common economic activities and living under a single roof. It consists of two or more members associated, and sharing common kitchen and have blood relation. The table below shows the types of families in the study area

Fig No. 1: Types of family of the respondents

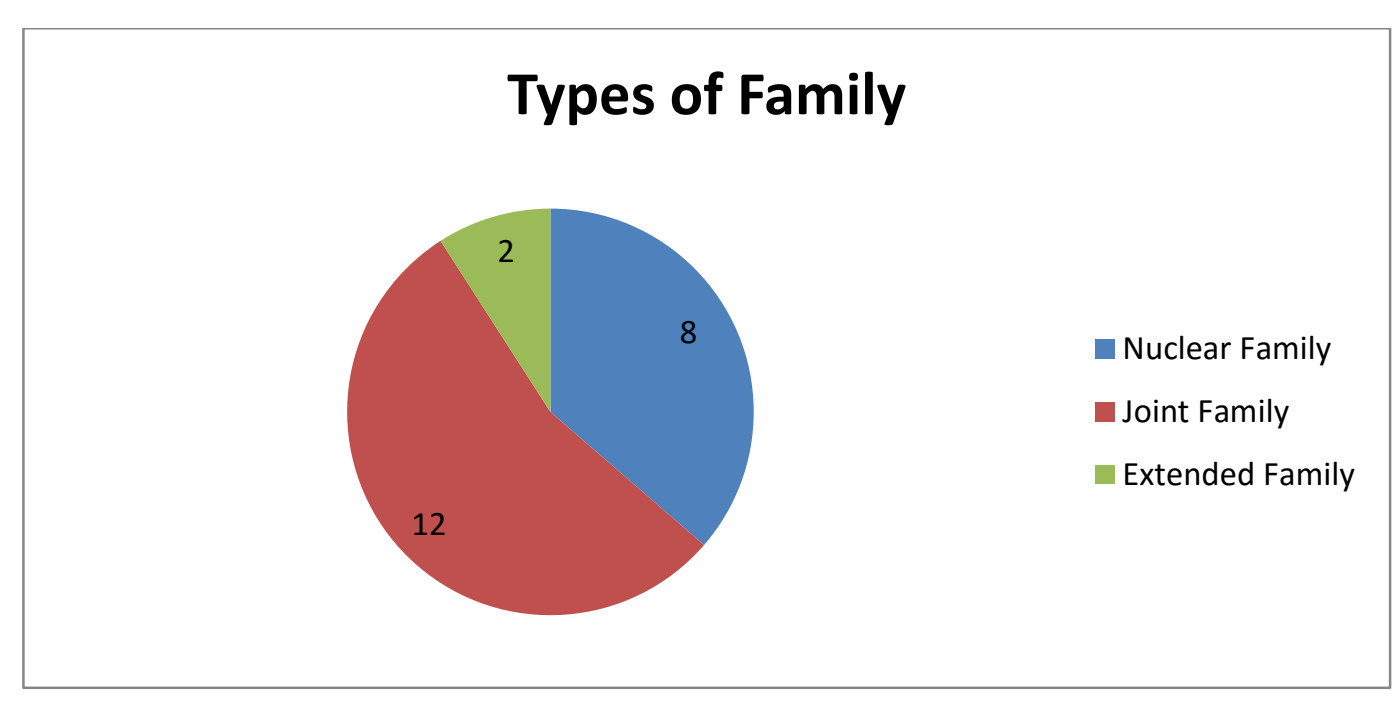

Source: Field survey, 2015.

The figure above depicts information of the type of family. According to the fact numbers of respondents living in joint family is $12(54.54 \%$ ) which is the highest number among the respondents. Similarly, nuclear family occupies 8 (36.36\%) followd by extended family 2 (9.09\%). It seems that most of the people live in joint family because of influence of traditional culture which is the most important key factor of transformation in the formation of family type. In some rural area of VDC, still we can observe joint family but whenever they get married they start to split into nuclear family. It is obvious that in the present world extended family hardly exists. But during our study we found two such families. Because of poverty, lack of education, and lack of earning sources these people are still living in a single family but it is very challenging for them to manage food, clothes and shelter. 
In the present world every individual should be equally responsible towards their family so they do not share their income except nearest family member which has created fraction in the family. More ahead, consumer societies, unnecessary competition, culture of show-off, and uncontrolled price hike are the crucial factors affecting family divisions. The pressure of sustaining family is one of the major reasons behind victimization as under such pressure victims can easily be lured and coerced. In this regard, size of family may be considered an influencing factor leading to victimization as Downey (1994) has mentioned family size also influences parental attitudes. For example, as family size increases, parents see themselves as less, and their children as more, responsible for funding college education, which may cause them leading towards the criminal activities leading to victimization.

\section{Marital Status of the respondents}

According to legal definition marriage is a contract made in due form of law, by which a free man and a free woman reciprocally engage to live with each other during their joint lives, in the union which ought to exist between husband and wife. By the terms freeman and freewoman in this definition are meant, not only that they are free and not slaves, but also that they are clear of all bars to a lawful marriage.

Generally, it is understood that marriage is a social bond in which two different sexes are united. However, same sex marriage has also been legitimized nowadays. According to the sociologist Ember and Ember "Marriage is a socially approved sexual and economic union between a man and a woman that is presumed to be more or less permanent, and that subsumes reciprocal rights and obligations between two spouses and between the spouses and their children." Marriage opens a gateway to new life as the husband and wife in which they have a new status and identity in the society after marriage. The table below depicts marital situation of the respondents in the study area.

Table No. 5: Marital status of the respondents

\begin{tabular}{|l|l|l|l|}
\hline S.N. & Marital Status & No. of Respondents & Percentage \\
\hline 1 & Married & 15 & $68.18 \%$ \\
\hline 2 & Unmarried & 7 & $31.82 \%$ \\
\hline & Total & $\mathbf{2 2}$ & $\mathbf{1 0 0}$ \\
\hline
\end{tabular}

Source: Field survey, 2015

The table above depicts the information regarding the situation of marital status of the respondents. Out of the 22 respondents $15(68.18 \%)$ are found married and $7(31.82 \%)$ are found unmarried. Most of them are found married because of the influence of culture and tradition and as well as to secure their rights and roles in the family. According to the tabulated data, the number of married is high among the respondents. The married people are mostly victimized as they have to bear family responsibilities At the same time, in case of any economic crisis, the 
crime rates may go up as Lafree (1998) has said that when basic social institutions (the family, economy, and political system) are in crisis, as during the 1960s and 1970s in the US, both property and violent crimes turn up; when these institutions regain legitimacy or other institutions (criminal justice, education) are strengthened, crime rates fall. (p. 289).

\section{Number of children of the respondents}

Traditional culture, religion and belief give the shape and size of the family. Nepalese culture is mainly influenced by Hindu religion. Religion and traditional belief one way or the other leads people to reproduce more children in the name of god, for the want of son and so on. The status of the number of children in the study area is presented here:

\section{Fig. No 2: Number of children of the respondents}

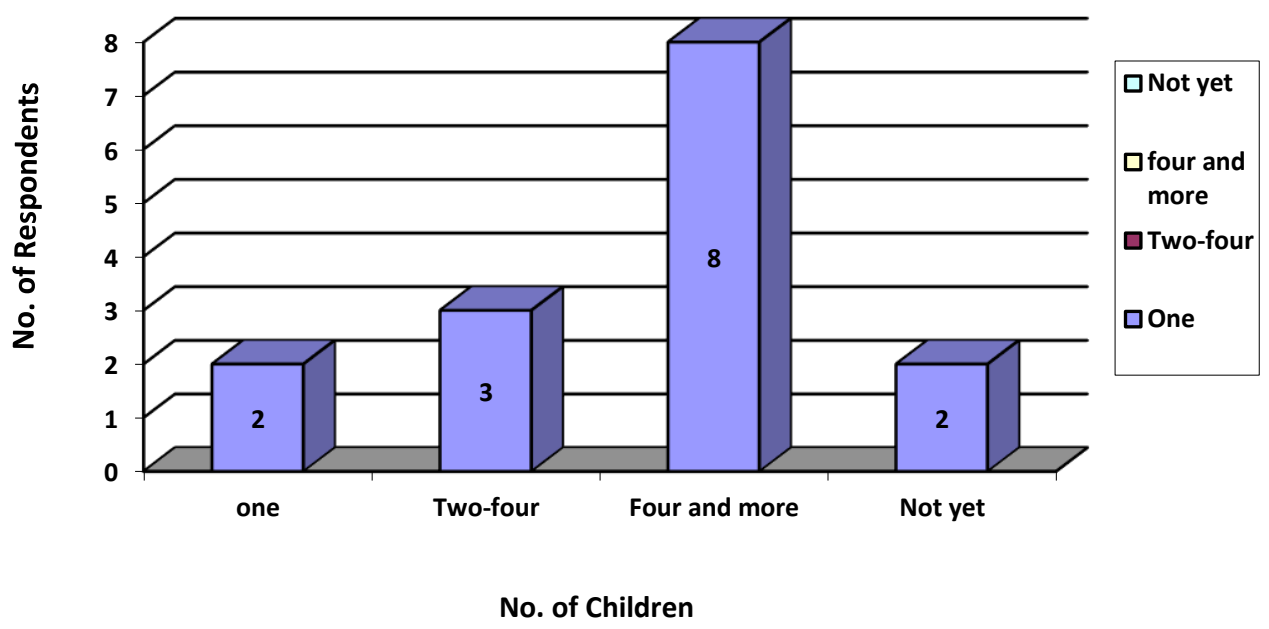

Source: Field survey, 2015

The figure above delivers information about the number of children of the respondents. The percentage of the respondents having only one child is 2. Similarly, having two-four children is 3 followed by having four and more children by 8 and 2 percent don't have children yet. The data tells that more numbers of respondents have four and more children in the study area that is because of the lack of awareness, traditional belief, and religious value. Moreover, some respondents have three or more numbers of children which denote that such families are guided by their culture and tradition, desire of son in the family some are unaware about the family planning methods, and so on. 
Similarly, it is also found that some parents have two children because of high child mortality rate. Here, not applicable means respondents whether unmarried or having no child.

\section{Literacy rate of the respondents}

Sharing knowledge and skill among one another is education. It is considered as the third eye of human being which enables people to take part in socio-economic as well as developmental affairs through legal process. The poor and downtrodden children are still deprived of education. Those who can simply read and write the basic alphabet are placed here as literate in this study. Situation of literacy rate and completion of secondary level by the respondents is portrayed from the following table;

Table no. 6: Educational status of the respondents

\begin{tabular}{|l|l|l|l|}
\hline S.N. & Educational attainment of the respondents & No. of respondents & Percentage \\
\hline 1 & Literate & 17 & $77.27 \%$ \\
\hline 2 & Illiterate & 5 & $22.73 \%$ \\
\hline & Total & 22 & 100 \\
\hline
\end{tabular}

Source: Field survey, 2015

The table above gives information about the educational status of the respondents. Literacy among the respondents has been reflected through the above table. Most of the respondents are found literate i.e. $77.27 \%$, on the other hand $22.73 \%$ people are still found to be illiterate in the study area. From the above data we can analyze that literacy rate of the study area is far better than the literacy rate of district as well as of the entire nation. When people are literate at least they can read and write simple letter and do numerical problems which enables them to do their household activities and to be aware about the legal status of the people and country. But literacy alone cannot fulfill the needs of the people. As per the data we can assume that lack of education might be the reason behind their victimization as we know that education has great importance to reduce crime and victimization ratio by raising level of awareness among people. Supporting the fact Lochner (2004) has said that the idea that education and training raise skill levels and wage rates, which then lowers crime.

\section{Income Source of the respondents}

Occupation is a nature of profession that teaches way of survival to everyone. Different occupations are chosen by people as per compulsion or convenience. The main occupation of the people in Surunga VDC is agriculture, business and Service. Very few are involved in government job, which is considered as the most prestigious job. The information below based on occupation is presented in the table.

Table No.7: Occupation of the respondents in the study area

\begin{tabular}{|c|c|c|c|}
\hline S.N. & Occupation of the respondents & No. of respondents & Percentage \\
\hline
\end{tabular}




\begin{tabular}{|c|c|c|c|}
\hline 1 & Agriculture & 10 & $45.45 \%$ \\
\hline 2 & Business & 4 & $18.18 \%$ \\
\hline 3 & Service & 3 & $13.64 \%$ \\
\hline 4 & Others & 5 & $22.73 \%$ \\
\hline & Total & 22 & $100 \%$ \\
\hline
\end{tabular}

Source: Field survey, 2015

The table above furnishes the information regarding the occupation of the respondents in the study area. According to the data, highest numbers of people $(45.45 \%)$ have taken up agriculture as the main occupation. Similarly, business covers $18.18 \%$ followed by service $13.64 \%$. Beside these $22.73 \%$ people are engaged in other activities such as labor, seasonal employment in factories, etc.

We come to know from the analysis of data that scientific methods are not introduced in the field of agriculture in the study area through unscientific way which creates poverty and dependency on others. Though Nepal is an agricultural country but still most of the farmers do not produce yields sufficient for them throughout a year. Most of the people who involve in agriculture are found depressed from the production because whatever they produce that is not enough to meet the needs of their families which reduce their interest in agricultural activities. As a result, they stay unemployed which creates economic crisis and makes their mind vacant and that may lead them to develop evil thoughts as Britt has explained that the economic hardship and/or the frustration and strain that people experience when they are unable to obtain or to maintain employment at the same time they want to maintain or to improve their standard of living and that leads people towards crime. If so, victimization certainly would increase (1997)

\section{Victimization of the respondents by types of crime}

Society cannot be completely free from the crime. Society is the combination of various families with the people of various natures. Every member of the society has their individual identity. By the reason, people in the society are being victimized by different crimes, not by the same one. The situation of victimization of the people is presented below on the basis of types of crime.

Table No. 8: Distribution of respondents by types of crime

\begin{tabular}{|c|c|c|c|c|c|}
\hline \multirow{2}{*}{ S.N. } & \multirow{2}{*}{ Types of crime } & \multicolumn{2}{|c|}{ Sex } & \multirow{2}{*}{ Total } & \multirow{2}{*}{ Percent } \\
\cline { 3 - 4 } & & Male & Female & & \\
\hline 1. & Human Trafficking & 0 & 3 & 3 & $13.63 \%$ \\
\hline 2. & Forgery & 2 & 0 & 2 & $9.09 \%$ \\
\hline 3. & Domestic Violence & 0 & 4 & 4 & $18.18 \%$ \\
\hline 4. & Property & 2 & 0 & 2 & $9.09 \%$ \\
\hline 5. & Sexual Offence & 0 & 7 & 7 & $31.82 \%$ \\
\hline
\end{tabular}




\begin{tabular}{|c|c|c|c|c|c|}
\hline 6. & Against Person & 4 & 0 & 4 & $18.18 \%$ \\
\hline & Total & $\mathbf{8}$ & $\mathbf{1 4}$ & $\mathbf{2 2}$ & $\mathbf{1 0 0}$ \\
\hline
\end{tabular}

Source: Field survey, 2015.

The data above reveals that respondents are mostly victimized by sexual offences which displays with the percentage of 31.82. Among the respondents, domestic violence and crimes againstperson both are at $18.18 \%$. Likewise, of the respondents, $13.63 \%$ are the victims of human trafficking and $9.09 \%$ of forgery and property.

The data shows that the study area is plagued with the criminal activities that victimize women. Sexual Offence, human trafficking, domestic violence are major problems. Women are considered as physically, economically and politically weak which increases chances of victimization. Supporting the fact that GESI report (2013) has mentioned that the traditional patriarchal structure of the society and structural discrimination against women contribute to reduce their social and economic status in Nepal. Much more to say they are not given much priority to give better education as a result they are seen weak in the family as Rao, (1987) has mentioned that education of children is a conscious and deliberate effort. Education of male children is given a fairly high priority by most of the parents because they recognize their education not only as an instrument to stay afloat in the competition that would ensue in their adult life, but also as a source of support in their old age. Thus the parents are willing to go into debt for their son's education he will later earn and pay back the debt.

\section{First information of the event}

It is very important to inform about the event to get the justice properly. Any of the case can be handled properly and systematically if the information of the event is given properly and at the right time. To get right justice and proper compensation, victim should be conscious while transforming the information. They should inform to the concerned authorities about the crime or event. The situation of providing the first information in the study area is shown by the following chart.

Table No. 8: First information of the respondents in the study area

\begin{tabular}{|l|l|l|l|}
\hline S.N. & Information Place & No. of respondents & Percentage \\
\hline 1 & Police & 18 & $81.82 \%$ \\
\hline 2 & Relatives & 2 & $9.09 \%$ \\
\hline 3 & Neighbor & 1 & $4.54 \%$ \\
\hline 4 & Media & 0 & $0 \%$ \\
\hline 5 & Public & 1 & $4.54 \%$ \\
\hline & Total & $\mathbf{2 2}$ & $\mathbf{1 0 0 \%}$ \\
\hline
\end{tabular}

Source: Field survey, 2015

The table above shows that 81.82 percent of the respondents share the data first to the police and 9.09 percent to relatives. 4.54 percent respondents share information to neighbor and media. 
The first information of the crime is the major problem in many cases because people hesitate to inform due to many reasons. Firstly, they are afraid to be exposed in family and society. Mainly the person who is victimized, fears exposure mentally, which lasts long. This mental fear may lead to economic failure. In this regard, Biderman, (1981) has exclaimed that the durable consequences of victimization, strangely enough, is far more common for psychic than for physical or material consequences as well as victimization affects later fear and anxiety and problems of psychic adjustment. If they are ready to inform, even they may not put in the right place. But in the study area people seem aware about the proper place so most percentage is to inform the police which is right authority to inform about the crime.

\section{Victim waiting for the justice (Duration to get the justice)}

It is not easy to get justice in our country because of lengthy legal procedure as well as political pressure cannot let judiciary to be independent as Shrestha (2007) has coined that regarding the contribution of the judiciary, it is always a subjective evaluation. As has been mentioned earlier, the nature of judicial process has been definite, but its working and the necessary environment for its smooth functioning have been influenced by the political upheavals. The influence of political cross currents is more pronounced during the constitutional change. People are unaware about the event, registration of the case and the procedure of the court. Numbers of the cases have been waiting to be decided in the court, by the reason people usually have to wait very long to get justice. That was even found in the study area which can be observed from the following table.

Table No. 9: Victims waiting for the Justice

\begin{tabular}{|l|l|l|l|}
\hline S.N. & Waiting Duration & No. of respondents & Percentage \\
\hline 1 & 1 month & 5 & $22.73 \%$ \\
\hline 2 & $1-12$ months & 4 & $18.18 \%$ \\
\hline 3 & 1year-2years & 8 & $36.36 \%$ \\
\hline 4 & 2years and more & 3 & $13.64 \%$ \\
\hline 5 & Decided & 2 & $9.09 \%$ \\
\hline & Total & $\mathbf{2 2}$ & $\mathbf{1 0 0 \%}$ \\
\hline
\end{tabular}

Source: Field survey, 2015

The data in the table revels that 36.36 percentage victims have been waiting to get the justice since two years though the nature of the cases are to be decided in very short time. The victims who are waiting a month are 22.73 in percentage because their natures of cases are to be decided within a month. Waiting for one year and two years and more have 18.18 and 13.64 respectively. Likewise 9.09 percent respondents got the decision in their cases. The data clearly explicit that court of Nepal is not free from criticism as kharel et. al. has reported that late decisions, problem in decisions' implementation as well as expensive legal procedure to justice for the poor, child, 
ISSN: 2362-1303 (Paper) | elSSN: 2362-1311(Online)

JOURNAL OF ADVANCED ACADEMIC RESEARCH (JAAR)

Jan 2016

old and women always plays role to delay the court decision which means as same as to have no justice. (2072)

\section{CONCLUSION}

Socio-economic status of the people in the society plays an important role in the process of crime and criminal activities. The criminal events and victimization processes are directly related with the socio-economic condition of the people. The society with sound socio-economic status has been facing the fewer numbers of crimes and victimization. The traditional culture and beliefs in the family, lack of education and awareness, gender discrimination, large family size as well as unemployment, traditional system of agriculture, and low income generation have created the criminal activities increasing the victimization in the society. Complex, lengthy and expensive court procedure as well as lack of security of the victims and their dependents prevents people from providing information regarding the crime which obstructs the process of justice.

\section{REFERENCES}

Bari, F. (2005, Nov). Women's Political Participation: Issues and Challenges. Bangkok, Thailand: EGM/WPD-EE/2005/EP.12.

Biderman, A. D. (1981, Summer). SOURCES OF DATA FOR VICTIMOLOGY. THE JOURNAL OF CRIMINAL LAW \& CRIMINOLOGY, 72(2), 789-817.

Britt, C. L. (1997, Dec). Reconsidering the Unemployment and Crime Relationship: Variation by Age Group and. Journal of Quantitative Criminology, Vol. 13, No. 4 (December 1997), pp. 405-428, 13(4), 405-428.

Douglas B. Downey, P. B. (1994, Feb). Sons versus Daughters: Sex Composition of Children and Maternal Views on Socialization. The Sociological Quarterly, Vol. 35, No. 1 (Feb., 1994), pp. 33-50, 35(1), 33-50.

G, L. (1998). Losing legitimacy:street crime and the decline of social institutions in America. Westview: Springer.

Hale, C. a. (1991). Testing the Relationship between Unemployment and. Journal of Research in Crime and Delinquency, 17-28.

Hirschi, T. (1969). The Causes of Delinquency. Berkeley: University of California Press.

Jarjoura, D. A. (1989, Nov). Household Characteristics, Neighborhood Composition and Victimization Risk. Social Forces, Vol. 68, No. 2 (Dec., 1989), 68(2), 621-640. 
ISSN: 2362-1303 (Paper) | elSSN: 2362-1311(Online)

kharel, R., Kunwor, T. N., Parajuli, S. P., \& Kunwor, L. B. (2072). Judicial Outrech programmee: a final guideline. NJA, Ministery of Law. kathmandu: National Judicial Academy.

Lamond, G. (2007, Winter). What Is a Crime? Oxford Journal of Legal Studies,, 27(4), 609-632.

Lochner, L. (2004, Aug). Education, Work, and Crime: A Human Capital Approach. WILEY,Institute of Social and Economic Research, 45(3).

McKeown, J. E. (1948, Nov. - Dec). Poverty, Race and Crime. Journal of Criminal Law and Criminology, 39(4).

Pant, D. P., Hamal, R., Thapa, N., Panta, S., Rana, K., \& Poudel, P. (2013). Gender Equality and Social Inclusion Analysis. kathmandu: National Judicial Academy, Nepal.

Rao, N. U. (1985). Women in Developing Society. New Delhi: Ashis Publishing.

Sookram, K. G. (2008). The Socio-economic Determinants of Violent Crime in Jamaica. Tobago: Sir Arthur Lewis Institute of Social and Economic Studies, The University of the West Indies, St. Augustine,

UN . (1985). UN Basic Principles . 